\title{
TO ESTIMATE THE PREVALENCE OF MICROALBUMINURIA IN NON-DIABETIC PATIENTS WITH CORONARY ARTERY DISEASE (CAD)
}

\author{
Bongu Srinivasa Rao1, A. Gopal Rao², Sharath Babu Naik Z3 \\ ${ }_{1}^{1}$ Associate Professor, Department of Medicine, RIMS, Srikakulam. \\ ${ }^{2}$ Associate Professor, Department of Medicine, RIMS, Srikakulam. \\ ${ }_{3}^{3}$ Assistant Professor, Department of Community Medicine, RIMS, Srikakulam.
}

\begin{abstract}
BACKGROUND
New WHO report Global atlas on cardiovascular disease prevention and control, 19 September 2011, states that coronary artery disease is the leading cause of death and disability in the world. Microalbuminuria may be a marker of generalised vascular disease with Arterial Endothelial Dysfunction being involved in the pathogenesis of atherothrombotic vascular disease.(1,2) Albumin is increasingly recognised as the earliest sign of vascular damage in both the kidney and the heart. Microalbuminuria may be a marker of generalised vascular disease with arterial endothelial dysfunction being involved in the pathogenesis of atherothrombotic vascular disease. Studies have shown Microalbuminuria is positively associated with Ischaemic Heart Disease(3) in non-diabetic subjects and can be regarded as an important additional risk factor for Ischaemic Heart Disease. Microalbuminuria is an important cardiovascular and mortality risk factor,(4) irrespective of diabetes or hypertension.(5) Microalbuminuria seems to reflect a state of pathophysiologic vascular dysfunction that makes an individual susceptible to organ damage.
\end{abstract}

ABSTRACT

\section{MATERIALS AND METHODS}

Cross-sectional hospital-based study.

Sample Size- Convenient sampling method was used till 60 study subjects were included. Sixty non-diabetic subjects of both sexes with coronary artery disease admitted as inpatients in Rajeev Gandhi Institute of Medical Sciences Hospital and Research Institute during the study period between May 2014 and July 2015 were included.

\section{RESULTS}

In this study, the prevalence of Microalbuminuria among CAD patients without Diabetes mellitus is $88.3 \%$ with high statistical significance in the age group of $30-60$ yrs. (40\%) followed by more than 60 yrs. (30\%), $41-50$ yrs. (20\%) and less than 40 yrs. $(10 \%)$. This suggests that CAD is more common after 50 yrs. of age. The mean age is $55.13+9.95$ yrs.

\section{CONCLUSION}

In this study, majority of subjects were males $(78.3 \%)$ and $(21.7 \%)$ were females. This observation was statistically significant. $66.7 \%$ of CAD subjects had positive family history of CAD. This observation was statistically significant. 58.3\% had smoking history. In this study, $61.7 \%$ of subjects presented with prevalence of Microalbuminuria. Among CAD patients without diabetes was 88.3\%. This observation was statistically significant. Mean microalbumin levels was $56.9 \pm 30.4$ mg. There was significant association between smoking and microalbuminuria among CAD subjects in the study.

\section{KEYWORDS}

Microalbuminuria, CAD, Smoking, Hypertension, Obesity, CAG, Lipid Profile.

HOW TO CITE THIS ARTICLE: Rao BS, Rao AG, Naik SBZ. To estimate the prevalence of microalbuminuria in non-diabetic patients with coronary artery disease (CAD). J. Evolution Med. Dent. Sci. 2018;7(03):394-396, DOI: 10.14260/jemds/2018/87

\section{BACKGROUND}

In microalbuminuria, abnormally high amounts of albumin in the urine is commonly thought of as an important risk factor for kidney disease. But recently studies have emerged highlighting microalbuminuria as an important, independent marker for endothelial dysfunction and CVD.(6) Heightened awareness of microalbuminuria as an early prognostic indicator(4) of CVD risk knowing when, how and in whom to screen for it and finally knowing the strategies to manage it

'Financial or Other Competing Interest': None.

Submission 13-11-2017, Peer Review 01-12-2017,

Acceptance 06-01-2018, Published 13-01-2018.

Corresponding Author:

Dr. Sharath Babu Naik Z,

Assistant Professor,

Department of Community Medicine,

RIMS, Srikakulam.

E-mail: bhavyabongu@gmail.com

DOI: $10.14260 /$ jemds/2018/87

(c) (i) (3) $\Theta$ are therefore essential prerequisites for cardiologists and other healthcare providers. $(4,7,8)$

\section{Microalbuminuria}

The urinary protein called albumin is increasingly recognised as the earliest sign of vascular damage in both the kidney and the heart. Microalbuminuria does not directly cause cardiovascular events. It serves as a marker for identifying those who may be at increased risk.(9)

According to Steno hypothesis, albuminuria might reflect a general vascular dysfunction and leakage of albumin and other plasma macromolecules such as low density lipoproteins into the vessel wall that may lead to inflammatory responses and in turn start the atherosclerotic process. ${ }^{(10)}$

Hence, a study was conducted to know the prevalence of Microalbuminuria among the CAD patients. 


\section{Aim of the Study}

1. To estimate the Prevalence of Microalbuminuria in nondiabetic patients with Coronary Artery Disease (CAD).

2. To study the association between Microalbuminuria and other risk factors for Coronary Artery Disease.

\section{MATERIALS AND METHODS}

\section{Study Design}

A cross-sectional hospital-based study to estimate the prevalence of microalbuminuria in non-diabetic patients with CAD.

Sample Size: All the study subjects who are admitted in the general medicine ward of RIMS Hospital with CAD were included till a sample of 60 was reached. Sample size was estimated by convenient sampling method.

\section{Inclusion Criteria}

- CAD patients based on coronary angiogram.

- Both sexes.

- Non-diabetic patients.

\section{Exclusion Criteria}

- Individuals with h/o known diabetes.

- H/o of renal diseases.

\section{Study Period}

From May 2014 - July 2015.

\section{Sampling Collection Procedure}

The patients were given a container for collection of urine over 24 hours, which was sent for the estimation of albumin level by immunoturbidimetric method. In this study, only inpatients who were diagnosed to have CAD by coronary angiogram were included.

\section{Statistical Methods}

Percentages, proportions and Chi-square tests were applied wherever applicable. SPSS 20.0 version was used for data analysis.

\section{RESULTS}

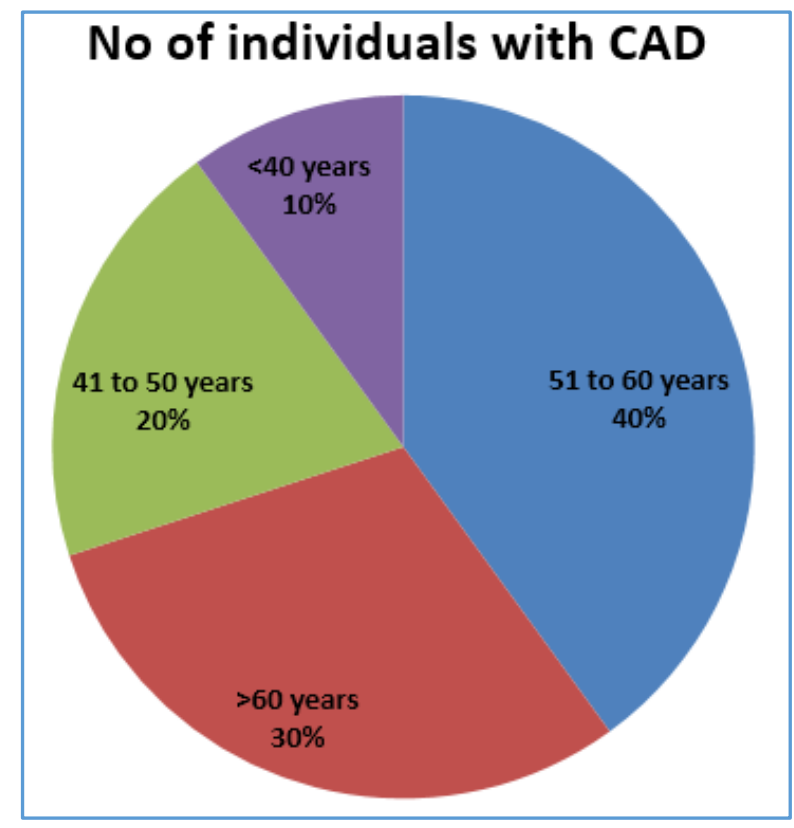

Table showing Findings of the Study

\begin{tabular}{|c|c|c|c|}
\hline & $\begin{array}{c}\text { Study } \\
\text { Subjects } \\
\text { (Percent) } \\
n=60 \\
\end{array}$ & $\begin{array}{c}\text { Microalbuminuria } \\
\text { Present } \\
\text { (Percent) } n=53\end{array}$ & Remarks \\
\hline $\begin{array}{l}\text { Family history } \\
\text { of CAD present }\end{array}$ & $40(75)$ & $37(69.8)$ & \multirow{2}{*}{$p>0.05$} \\
\hline $\begin{array}{c}\text { No family history } \\
\text { of CAD }\end{array}$ & $20(25)$ & $16(30.1)$ & \\
\hline $\begin{array}{l}\text { H/o smoking } \\
\text { present }\end{array}$ & $35(58.3)$ & $34(64.1)$ & \multirow[t]{2}{*}{$\mathrm{p}<0.05$} \\
\hline No h/o smoking & $25(41.7)$ & $19(35.9)$ & \\
\hline
\end{tabular}

\section{DISCUSSION}

Albuminuria has been identified as a life-threatening and cardiovascular renal risk profile. This important diagnostic parameter cannot only predict renal or concurrent renal and cardiovascular adverse events in high-risk patients.

\section{Age Distribution}

In this study majority of subjects were in the age group of 50 to 60 yrs. (40\%) followed by $>60$ years (30\%), 41 to 50 years $(20 \%)$ and $<40$ years $(10 \%)$. This suggests that CAD is more common after 50 years of age. There was significant difference in proportions. The mean age is $55.13 \pm 9.95$ years.

\section{Gender Distribution}

In this study, majority of subjects were males (78.3\%) and rest were females (21.7).

\section{Family History of CAD}

In my study, $66.7 \%$ of CAD subjects had family history of CAD. There was no significant association between family h/o CAD and Microalbuminuria among CAD subjects in the study.

\section{Smoking}

In this study, $58.3 \%$ of subjects had history of smoking. There was significant association between smoking and microalbuminuria among CAD subjects in the study.

\section{BMI}

There was no significant association between BMI and microalbuminuria among CAD subjects in the study. Odds ratio was 1.19 , i.e. CAD subjects with $\mathrm{BMI}>23$ are at 1.19 times higher risk for microalbuminuria than subjects with $\mathrm{BMI}<23$, but the risk was not statistically significant.

In this study, there was significant association between hypertension and microalbuminuria among CAD subjects in the study. $69.8 \%$ hypertensive subjects and $30.2 \%$ normotensive subjects had microalbuminuria.

\section{Lipid Profile}

In my study, there was no significant association between total cholesterol and microalbuminuria among CAD subjects in the study.

\section{Microalbuminuria and CAD}

Prevalence of Microalbuminuria among CAD patients without diabetes was $88.3 \%$. This observation was highly statistically significant $(\mathrm{p}<0.001)$. Mean microalbumin levels was $56.9 \pm$ $30.4 \mathrm{mg}$. 
In Danish Hospital, a study done by Jensen JS, FeldtRasmusen concluded microalbuminuria as an independent risk factor for IHD among hypertensive individuals who are non-diabetic.(11) The studies done by Diercks et al(12) and Hillege et al(13) in large population using Univariate and Multivariate logistic regression analysis have shown Microalbuminuria is independently associated with increased cardiovascular risk factors and cardiovascular morbidity. Even in the present study, there is a strong association between Microalbuminuria and CAD. But Microalbuminuria could not be established as an independent risk factor for CAD, since the study evaluated a lesser number of subjects.

\section{CONCLUSION}

- In this study, the prevalence of Microalbuminuria among CAD patients without Diabetes mellitus is $88.3 \%$ with high statistical significance. Mean urinary albumin excretion is $56.9 \pm 30.4 \mathrm{mg} / 24 \mathrm{hrs}$.

- Analyses of the association between the risk factors of CAD and Microalbuminuria showed that risk factors like Smoking has statistically significant association with Microalbuminuria.

- $\quad$ Risk factors of CAD like Age, High BMI and Dyslipidaemia did not have any significant statistical association with microalbuminuria.

- Microalbuminuria may therefore add value together with traditional risk indicators in diagnostic strategies.

- It is concluded that this study recommends estimating Urinary microalbumin excretion for 24 hours to identify high risk individuals for Coronary Artery Disease.

\section{REFERENCES}

[1] Gerstein HC, Mann JF, Yi Q, et al. Albuminuria and risk of cardiovascular events, death, and heart failure in diabetic and nondiabetic individuals. JAMA 2001;286(4):421-6.

[2] Beamer NB, Coull BM, Clark WM, et al. Microalbuminuria in ischemic stroke. Arch Neurol 1999;56(6):699-702.

[3] Bennett PH, Haffner S, Kasiske BL, et al. Screening and management of microalbuminuria in patients with diabetes mellitus: recommendations to the scientific advisory board of the national kidney foundation from an ad hoc committee of the council on diabetes mellitus of the national kidney foundation. Am J Kidney Dis 1995;25(1):107-12.
[4] Damsgaard EM, Frøland A, Jørgensen OD, et al. Microalbuminuria as predictor of increased mortality in elderly people. BMJ 1990;300(6720):297-300.

[5] Forman JP, Brenner BM. Hypertension and microalbuminuria: the bell tolls for thee. Kidney Int 2006;69(1):22-8.

[6] Gosling P. Microalbuminuria: a marker of systemic disease. Br J Hosp Med 1995;54(6):285-90.

[7] Karalliedde J, Viberti G. Microalbuminuria and cardiovascular risk. Am J Hypertens 2004;17(10):98693.

[8] Haffner SM, Stern MP, Gruber MK, et al Microalbuminuria. Potential market for increased cardiovascular risk factors in nondiabetic subjects? Arteriosclerosis 1990;10(5):727-31.

[9] Yuyun MF, Khaw KT, Luben R, et al. Microalbuminuria independently predicts all-cause and cardiovascular mortality in a British population: the European prospective investigation into cancer in Norfolk (EPIC-Norfolk) population study. Int J Epidemiol 2004;33(1):189-98.

[10] Deckert T, Feldt-Rasmussen B, Broch-Johnsen K, et al. Albuminuria reflects widespread vascular damage. The Steno hypothesis. Diabetalogia 1989;32(4):21926.

[11] Borch-Johnsen K, Feldt-Rasmussen B, Strandgaard S, et al. Urinary albumin excretion. An independent predictor of ischemic heart disease. Arterioscler Thromb Vasc Biol 1999;19(8):1992-7.

[12] Diercks GF, van Boven AJ, Hillege HL, et al. Microalbuminuria is independently associated with ischaemic electrocardiographic abnormalities in a large non-diabetic population. The PREVEND (Prevention of REnal and Vascular ENdstage Disease) study. Eur Heart J 2000;21(23):1922-7.

[13] Hillege HL, Janssen WM, Bak AA, et al. Microalbuminuria is common, also in a nondiabetic, nonhypertensive population, and an independent indicator of cardiovascular risk factors and cardiovascular morbidity. J Intern Med 2001;249(6):519-26. 